International Journal of Social Science and Economic Research

ISSN: 2455-8834

Volume:06, Issue:07 "July 2021"

\title{
ART THERAPY: THERAPEUTIC FORM OF EXPRESSION
}

\author{
DEVESHI MALHOTRA
}

BSc Social Science, University College London

DOI: 10.46609/IJSSER.2021.v06i07.009 URL: https://doi.org/10.46609/IJSSER.2021.v06i07.009

\section{ABSTRACT}

Art is defined as the creation of forms symbolic of human feelings. It is a creative method of self-expression and communication. Art records and preserves emotions, helps in selfunderstanding and personal growth. Art therapy on the other hand, a term coined by British artist Adrian Hill in 1942, ais a hybrid discipline based on Psychology and art to evolve a unique new entity (Malchiodi, 2003). Art therapy is an underrated form of treatment and my aim is to highlight its several benefits which I have done in my research paper. The results present art therapy to be an effective method of emotional expression and also an impactful method of treatment for people who are diagnosed with Post-traumaticstress disorder, and other personality related disorders.

Key Words: Art therapy, Expression, Emotions, Well-being, Therapeutic technique.

\section{Introduction}

Art therapy is "a modality for self-understanding, emotional change and personal growth." It has a cumulative culture and comes from the interweaving of art with social psychiatry and psychoanalysis (Gilroy, 2006). This therapeutic technique is based on the premise that artistic expression fosters healing and mental well-being. It is also referred to as 'Expressive art' or 'art psychology'. The credit for the growth of art therapy was given to Margaret Naumburg, also referred to as the "Mother of art therapy,". She was of the opinion that only those individuals who expressed themselves truly and pursued subjects of their interest would experience healthier development.

It is well known worldwide due to its benefits and because it has been used on a large percentage of the population. It had proved to be beneficial for all age groups: children, adults, the elderly as well as people with disabilities and psychological disorders (Malchiodi, 2003). It helps in treating people with personalitydisorders (Haeyen, et al., 2020), reducing stress, and irritability levels. An art therapist assists the client in achieving artistic self-expression and leads to the reflection of 
International Journal of Social Science and Economic Research

ISSN: 2455-8834

Volume:06, Issue:07 "July 2021"

problematic feelings through art (American Art Therapy Association, 2017). My hypothesis is that Art therapy helps build and increase self- awareness and self-esteem, and is a highly effective form of treatment.

\section{Art Therapy}

Art therapy can improve human mood, communication, and concentration which increases selfconfidenceand self-awareness (Petrillo and Winner, 2005). Through therapy people can express their feelings regarding any topic through creative work rather than with speech, and is believed to be particularly helpfulfor those who feel out of touch with their emotions or feelings. Art therapy acts as a catalytic agent, and is founded on an empathetic relationship extending both interpersonally and through interactions with artworks (Kapitan, 2010). Additionally, art contributes to mental health by giving individuals a sense of identity as well as expanding and directing human thought process (Congdon, 1990).

Individuals experiencing difficulty discussing or remembering painful experiences find art therapy relaxingand beneficial.

\subsection{Constructive advantages of Art therapy}

- Attenuates depression: Positivity and hope are fostered in people's lives by practicing art therapy. It is proven to help combat the chemical imbalances in the brain that may lead to depression. It has been found to be influential in dealing with patients with depression (Blomdahl, et al., 2016). Depression being a complex syndrome with symptoms such as low mood, low self-esteem, and performing art therapy acts as an important method of treatment for depression (Blomdahl, et al., 2016).

- Strengthens self-esteem: Art allows for the discovery of what makes people unique (Rhyne, 1973). It provides opportunities for healthy self-involvement which ultimately boosts ones self-esteem. Making art gives rise to a sense of accomplishment and increases levels of self-confidence(Franklin, 1992).

- Enhance communication skills: Individuals who find it difficult to cope up with personal and socialproblems turn to substance abuse to escape the harsh reality. Art therapy fosters self-expression and can help develop communication skills and the ability to reach out to others.

- Self - discovery: Engaging in the creative process helps in acknowledging and recognizing feelingsthat are present in our subconscious mind. It helps the individual get 


\section{International Journal of Social Science and Economic Research}

ISSN: $2455-8834$

Volume:06, Issue:07 "July 2021"

in touch with their primary processes, leads to the path of self-discovery, and fosters a healthy holistic personality (Waller, 2006).

- Diminishes stress: Art therapy helps in converting negative energy into positive habits by channelling the energy in a creative direction. Studies also show that creating art stimulates the release of dopamine. This chemical is released when we do something pleasurable, and it makes us feel happier. Increased levels of this feel-good neurotransmitter can be very helpful if one is battlingstress or depression.

\subsection{Techniques and methods}

Art therapy can be wildly liberating since there are no rules to follow and individuals can create an image they want, to express entirely what they feel. Requiring no specific artistic skill or inclination, is what makesthis therapy widely applicable. There are certain types of techniques:

- Painting: This activity gives is associated with a sense of freedom. The art therapist gives the individual certain prompts, on the basis of which he/she/they draw. Doodling scribbling, and collaging are other effective techniques that can be used (Snyder, 1997). Example: Drawing an emotion wheel. Example of collaging: making a collage about dream life and future goals.

- Sculpting: By making family sculptures, sculptures of different object, individuals get a chance to convert something seemingly mundane into something artistically appealing. Persons can use moulding clay, carving techniques and can also engage in pottery making.

- Active imagination: This technique devised by Carl Jung uses the images created by their patients to freely associate other thoughts or feelings that come spontaneously to their minds. The goal is to help clients gain a deeper understanding of themselves and their surroundings that fosters their growth.

- Gestalt methodology: Some therapists use Gestalt Psychology which focuses on 'form' and 'configuration' of an image (Rhyne, 2001). It focuses on looking at the image as a whole rather than in parts. This helps in identifying the broader picture and the themes associated with it.

- Third hand approach: The "Third-hand" approach is a term coined by art therapist Edith Kramer. The premise of the technique is that without distorting or impacting the client's artwork, the therapist should get involved in the process of creation to help them convey 
International Journal of Social Science and Economic Research

ISSN: 2455-8834

Volume:06, Issue:07 "July 2021"

an image to their best ability.

These different techniques have also been effective in revealing material that has been pushed down into an individual's subconscious by repression, providing cathartic release, and promoting verbal expression.

\section{Research Study}

Art therapy has a significant impact on people diagnosed with personality disorders. Researchers Haeyan, Van Hooren and Hutchemaekers worked to identify the effects of art therapy on the recovery process in groups of adults with personality disorders (Todorova, 2017). To do which they used existing anecdotal observations made by practitioners and patient testimonies. The Grounded Theory Approach - GTA (construction of theories by collecting and analysing data) was used by them to construct a qualitative study to collect data that reflected the responses of individual's to their personal experienceswith art therapy.

\subsection{The five concepts that summarised the data collected through the interviews}

- Perception and self-perception- Expression through art has helped people focus on the present moment, identify their emotional responses and body awareness (Todorova, 2017). These perceptions became the first step in recognizing and validating emotions and a starting point for further therapeutic explorations.

- Emotion and impulse regulation - Art therapy teaches individuals to modulate their emotional responses. It offers them an experiential space in which they experiment with new responses, ultimately increasing their self-confidence and self-efficacy. Example: If an individual enjoys working with numbers their self-efficacy for financial tasks will be high.

- Personal integration - Expression of their experiences helped people strengthen their identity and self-image, they developed a more optimistic outlook (Todorova, 2017). Art expressions madeemotions more visible, allowing them to further investigate feelings and thoughts within the courseof therapy. It also helps them reduce their stress level.

- Insight and comprehension - Art expression helped individuals to put their emotions and non-verbal experiences into an image (Todorova, 2017). People said that they "experienced an inner dialogue that guided their choices while working on the art product" as well as after the art expression was completed. Such an expression made the thoughts of a person more clear. 
- Behaviour change - This includes behaviour changes towards oneself and others. Individuals reportedly learned to change their behavioural responses through the process of art expression (Todorova, 2017). Additionally, art therapy provide an opportunity to practice alternative responsesto existing personal narratives.

\section{Expression through Art}

Expression through art is different for everyone. Example, when given the prompt 'Draw yourself as a tree' (Image representation below), children were seen drawing different representations and art therapy helps us in understanding these differences in a unique manner (Case and Dalley, 2014).

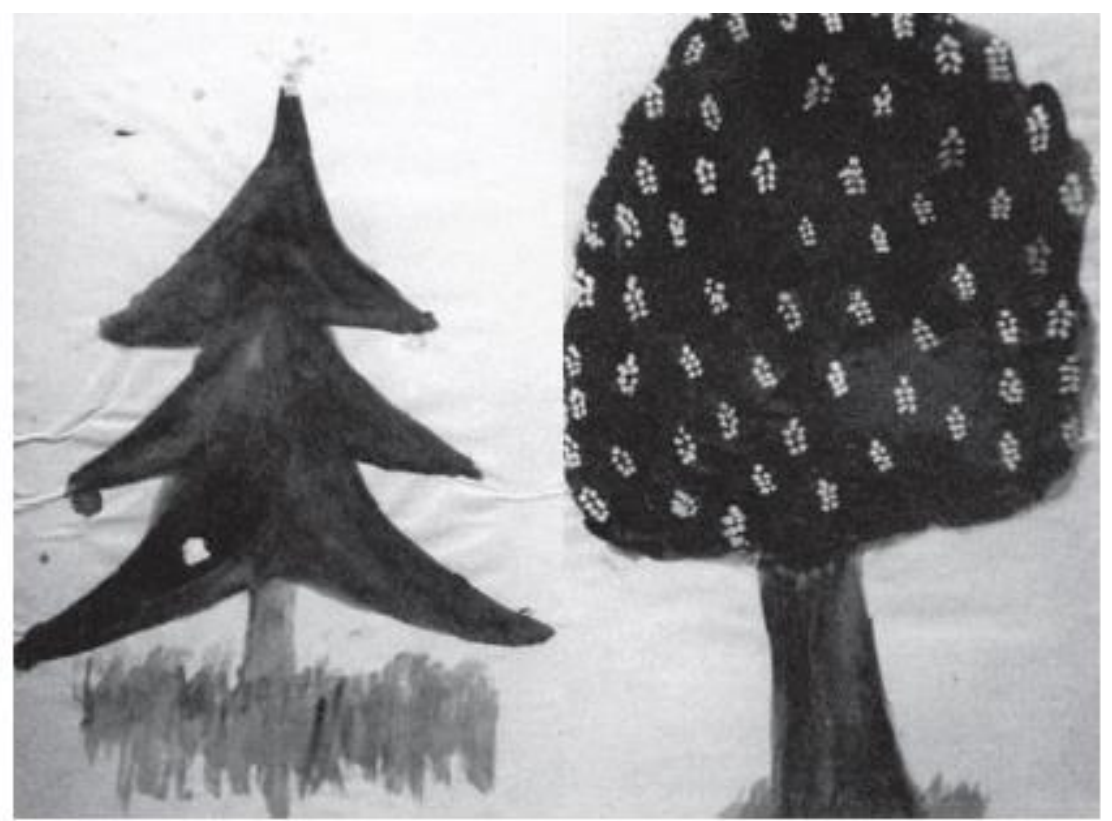

Fig 1. Pictorial Representation of the above prompt 

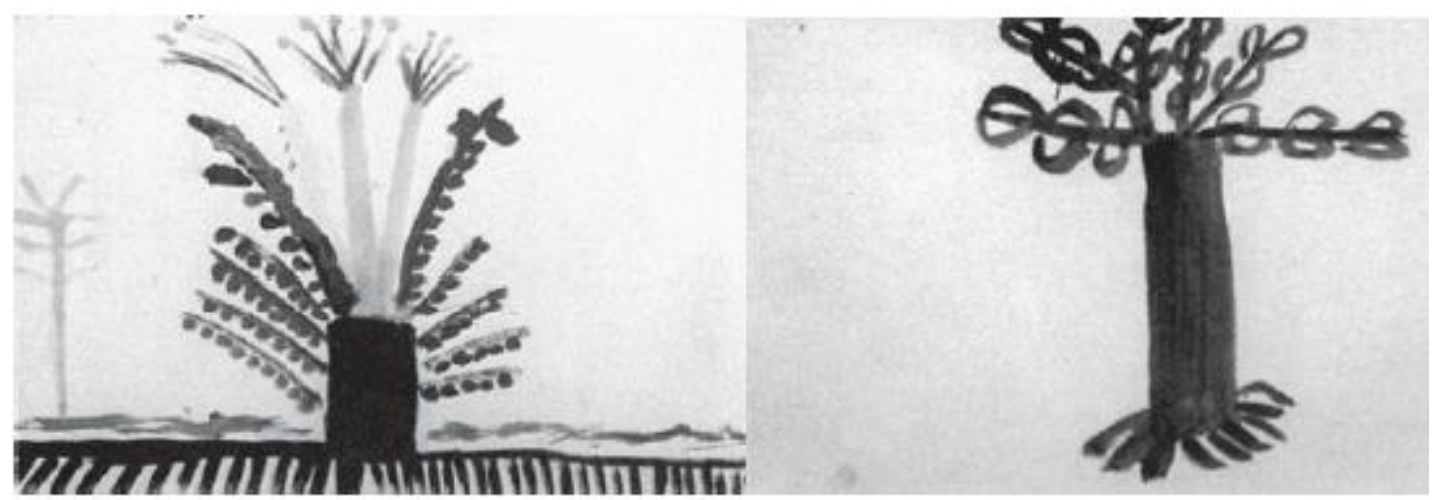

Fig 2. Pictorial Representation of the above prompt

\subsection{Art and the COVID-19 Pandemic}

Art therapy has been used a method for synthesizing human experiences along with feelings of isolation that people have experienced during the stressful times of the pandemic (Choudhry and Keane, 2020). Practicing art therapy helped individuals coped with stress, anxieties, trauma, and changes in the circumstances. Art therapists have been "essential workers" during the pandemic and $54.1 \%$ went for workin person (Choudhry and Keane, 2020)

"Corona on my Mind" by Michele D. Rattigan, Clinical Associate Professor of Art Therapy \& Counselling Graduate Program at Drexel University College. The piece represents the individual/collective, inside/outside, and micro/macro changes in a post-pandemic life (Choudhry and Keane, 2020). 


\section{International Journal of Social Science and Economic Research}

ISSN: $2455-8834$

Volume:06, Issue:07 "July 2021"

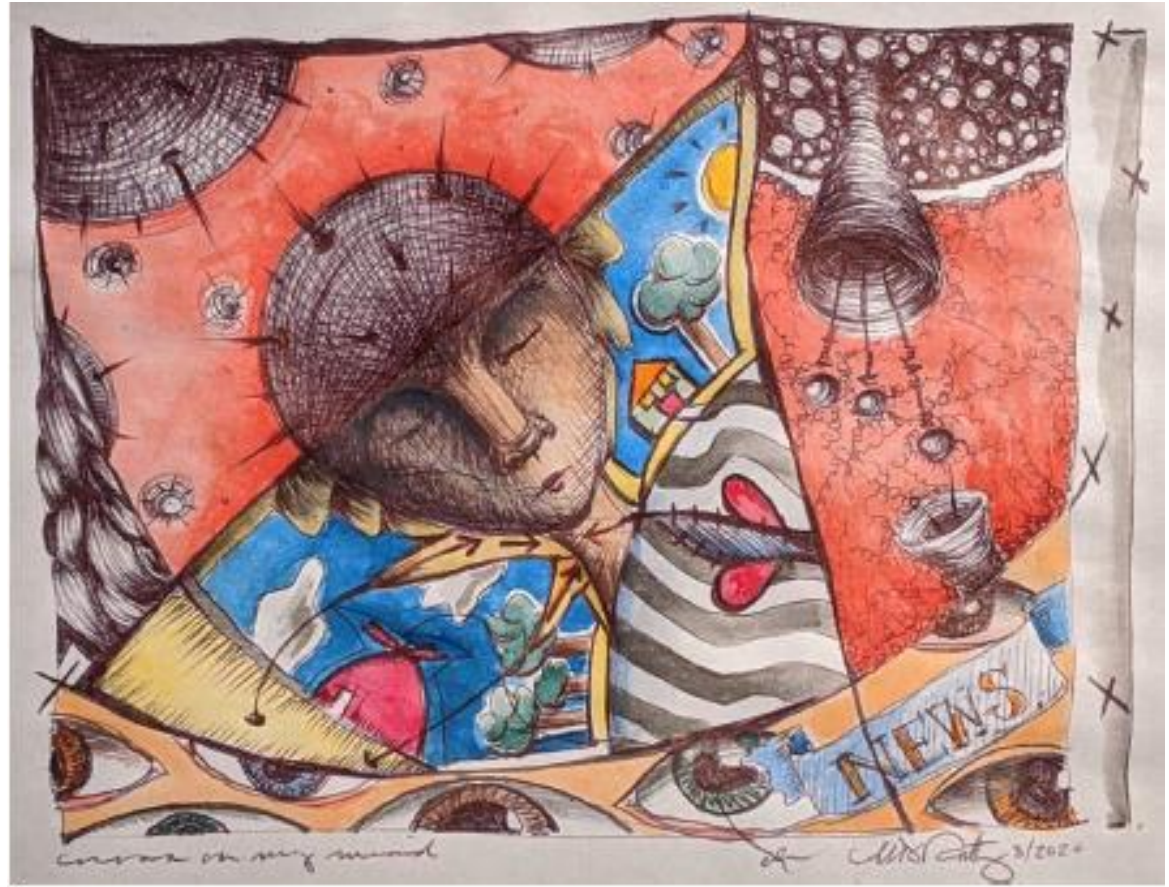

Fig 3. 'Corona on my Mind' by Michele D. Rattigan

\subsection{Effectiveness of art therapy}

The graph below makes comparison between the effectiveness of Art Therapy and Standard Therapy on patients who face Post traumatic stress disorder - PTSD (Chapman, et al., 2001). It is evident from the graphthat Art therapy is more effective as compared to regular therapy in this scenario. Additionally, the International Society for Traumatic Stress Studies provides a detailed study of how the creative art therapies treats as well as improves the sleep cycle of patients suffering from PTSD (ITSS, 2021). Therefore, art therapy interventions and treatment strategies are helpful in treating patients with PTSD. 
International Journal of Social Science and Economic Research

ISSN: 2455-8834

Volume:06, Issue:07 "July 2021"

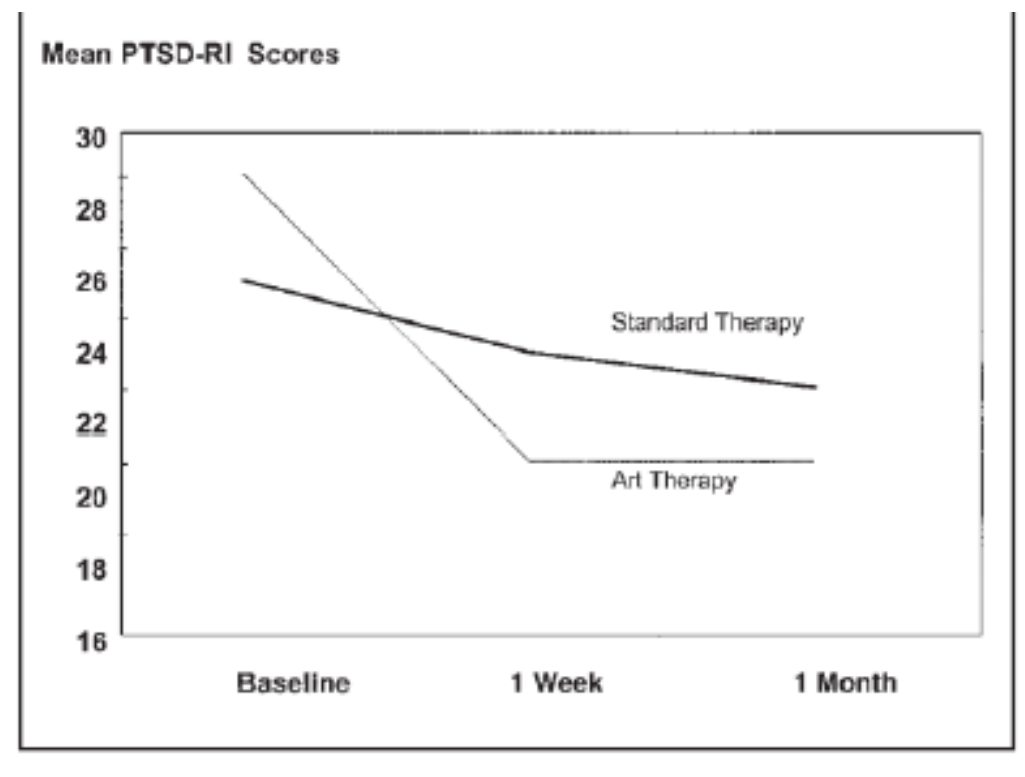

\section{Conclusion}

Art therapy has a number of benefits and its impact on individuals is remarkable. It not only helps in emotional expression but also is an effective method of treatment. Moreover, the feelings that rise from the subconscious mind are best expressed through visuals and images which is where Art therapy steps in. Thisdetailed analysis is consistent with my hypothesis and thus proves that Art therapy not only helps people inbuilding their self-confidence and self-esteem but is also a reliable and valid therapeutic technique of treating patients with severe personality disorders and other chronic illnesses.

Future research on Art therapy should focus on considering it as an importance mechanism for treatment of multiple disorders.

\section{References}

[1] American Art Therapy Association (2017). What is Art Therapy?. Available online at: http://arttherapy.org/

[2] Blomdahl, C. Birgitta A. G., Guregård, S., Rusner, M., Wijk, H., \& Björklund, A. (2016). Art therapy for patients with depression: expert opinions on its main aspects for clinical practice. Journal of Mental Health.

[3] Case, C., \& Dalley, T. (2014). The Handbook of Art Therapy, Third Edition. Taylor \& Francis Group. 
International Journal of Social Science and Economic Research

ISSN: 2455-8834

Volume:06, Issue:07 "July 2021"

[4] Chapman, L., Morabito, D., Ladakakos, C., Schreier, H., \& Knudson, M. (2001). The Effectiveness of Art Therapy Interventions in Reducing Post Traumatic Stress Disorder (PTSD) Symptoms in Paediatric Trauma Patients. Journal of the American Art Therapy Association, 18, $100-104$.

[5] Choudhry, R. \& Keane, C. (2020). Art therapy during a mental health crisis: Coronavirus Pandemic Impact Report. American Art Therapy Association May 2020 Survey.

[6] Congdon, K.G. (1990). Normalising Art Therapy. Art Education. National Art Education Association, 43, 18-24.

[7] Franklin, M. (1992). Art Therapy and Self-Esteem. Journal of the American Art Therapy Association.

[8] Gilroy, A. (2006). Art Therapy, Research and Evidence-based practice. SAGE Publications.

[9] Haeyen, S., Chakhssi, F., and Hooren, S.V., (2020). Benefits of Art Therapy in people diagnosed with Personality Disorders: A Quantitative Survey. Frontiers in Psychology.

[10] Kapitan, L., (2010). The Empathetic Imagination of Art Therapy: Good for the Brain? Journal ofthe American Art Therapy Association.

[11] Malchiodi, C.A. (2003). Handbook of Art Therapy. The Guilford Press Publications, New York.

[12] Petrillo, L.D. and Winner, E., (2005). Does art improve mood? A Test of a key assumptionunderlying Art Therapy. Journal of the American Art Therapy Association.

[13] Ponte, L. \& Jerome, L. 14 June 2021. MDMA-Assisted Therapy can improve Sleep Quality in PTSD. International Society for Traumatic Stress Studies. [online] Available from: https://istss.org/public-resources/trauma-blog/2021-june/mdmaassisted-therapy- can-improve-sleep-quality-in

[Accessed 5 July 2021].

[14] Rhyne, J. (1973). The Gestalt art experience. Monterey, CA: Brooks/Cole Publishing Company.

[15] Rhyne, J. (2001). The Gestalt Approach to experience, art and art therapy. American 
International Journal of Social Science and Economic Research

ISSN: 2455-8834

Volume:06, Issue:07 "July 2021"

Journal of Art Therapy, 12(4), 237-248.

[16] Snyder, B,A. (1997). Expressive Art therapy techniques: Healing the soul through creativity. Journalof Humanistic Education and Development.

[17] Todorova, G.A. (2017). Art Therapy in Nursing. Medical Science Pulse, 11(3).

[18] Waller, D. (2006). Art Therapy for Children: How it leads to change. Clinical Child Psychologyand Psychiatry, SAGE Publications. 